\title{
FEASIBILITY ANALYSIS OF DESIGN FOR REMANUFACTURING IN BEARING USING HYBRID FUZZY-TOPSIS AND TAGUCHI OPTIMIZATION
}

\author{
Vishal Fegade \\ SVKM's NMIMS Mukesh Patel School of Technology Management \& \\ Engineering, Mechanical Engineering Shirpur, India \\ E-mail:vishalfegade@gmail.com \\ Kshitij Shrivastava \\ Indian Institute of Technology Kharagpur, Ocean Engineering and \\ Naval Architecture, India \\ E-mail: krshrivastava@gmail.com
}

\author{
A. V. Kale \\ Yeshwantrao Chavan College of Engineering, Mechanical \\ Engineering, India \\ E-mail: avkale@ycce.edu \\ R. L. Shrivastava \\ Yeshwantrao Chavan College of Engineering, Mechanical \\ Engineering, India \\ E-mail: rlshrivastava@gmail.com
}

Submission: $12 / 22 / 2018$ Accept: 3/13/2019

\section{ABSTRACT}

The tremendous advancement in technology, productivity and improved standard of living has come at the cost of environmental deterioration, increased energy and raw material consumption. In this regard, remanufacturing is viable option to reduce energy usage, carbon footprint and raw material usage. In this manuscript, using computational intelligence techniques we try to determine the feasibility of remanufacturing in case of roller bearings. We collected used N308 bearings from 5 different Indian cities. Using Fuzzy-TOPSIS, we found that the roundness, surface roughness and weight play a vital role in design for remanufacturing of roller bearings. Change in diameter, change in thickness and change in width showed minimal influence. We also used Taguchi analysis to reassess the problem. The roundness of inner and outer race was found to be the most influential parameters in deciding the selection of bearing for remanufacturing. 
DOI: 10.14807/ijmp.v11i1.942

The results suggest the bearing designer to design the bearing in such a way that roundness of both races will be taken cared while manufacturing a bearing. However, using Taguchi the weight of the rollers was found to be of least influence. Overall, the predictions of Taguchi analysis were found to be similar to Fuzzy-TOPSIS analysis.

Keywords: Taguchi analysis; Fuzzy-TOPSIS; remanufacturing

\section{INTRODUCTION}

In earlier day's manufacturers used to ignore the used products and these scraps would eventually pose a landfill problem. However, due to recent stringent environmental rules manufacturer has to consider the end of life strategies for recycling of product (DINDARIAN et al., 2012). Sustainable remanufacturing is a critical tool required to improve the efficiency of a product recovery.

To have the necessary efficient and flexible remanufacturing system, part information and actual condition of product become vital at end of life. For efficient remanufacturing, challenges are the collection of cores, flexibility in process and redistribution of products (LIU, et al., 2016). Selection of components in remanufacturing always have some constraints with a specific objective, again at the time of selection one cannot estimate the consequences of the process accurately (PUROHIT; RAMACHANDRAN, 2015).

Remanufacturing is a systematic process to bring the product back into function. It includes sorting and inspection of components followed by disassembling the components for reprocessing (FEGADE; SHRIVATSAVA; KALE, 2015). Parts disassembled can be replaced if it cannot be repaired or reprocessed to meet the required quality and functionality.

Remanufacturing is beneficial to the environment as it diverts the scrap components from a landfill. It also requires less energy and material as compared to new component manufacturing (KENNE; DEJAX; GHARBI, 2012). Among all end of product life recycling strategies, remanufacturing is perhaps the most potent one as component returned through remanufacturing has specification nearly same as a new one.

Additionally, it saves time, material and energy imparted over the product. Higher quality of product remanufacturing provides longer life extension and viable products. Remanufacturing is a comprehensive industrial process by which a previously sold, worn, or non-functional product or module is returned to a "like-new" or "better than new" condition and warranted in performance level and quality (AYDIN; KWONG; JI, 2015). 
DOI: 10.14807/ijmp.v11i1.942

Remanufacturing, though still an evolving industry, holds many ecological and economic benefits. Remanufacturing is the complete or partial reconstruction or overhaul of a product to the original stipulation of reusable and repairable parts and replacing some completely worn out parts by new ones (BENKHEROUF; SKOURI; KONSTANTARAS, 2016).

Product recovery is to retrieve a product when the product no longer fulfills desired needs. Product recovery involves recycling, reuse and remanufacturing (HILGER; SAHLING; TEMPELMEIER, 2016). Integration of remanufacturing in closed loop supply chain as a significant end of life product recovery system could potentially generate benefits to both the business and the environment. For any company which manufactures and sell both new and remanufactured products, optimizing the product design is very difficult.

The design decisions taken at early stages have more influence on profits in manufacturing and remanufacturing (RAMACHANDRAN; AGARWAL, 2017). Remanufacturing has environmental benefits as well as significant potential to influence product economy in reverse logistic. Remanufacturing begins with identification and inspection of cores (scrap products) further disassembly, reconditioning, assembly and testing (ZHANG et al., 2011).

Inspections of cores are the critical activity which leads to the effectiveness of the remanufacturing. Remanufacturing is a generic term for technical renovation or engineering activities of waste products. In remanufacturing, a large number of inspections and evaluations of the failure conditions of the parts have to be done, which are uneconomical and inefficient (SUGUMARAN; RAMACHANDRAN, 2007).

After the inspection and selection of the parts, disassembly is the process which gives large impact in any remanufacturing system (FORD; DESPEISSE, 2016). It depends upon the volume of the returned product as volume increases this process becomes more significant because the efficiency of remanufacturing depends upon the effectiveness of the disassembly process (KWAK; KIM, 2015; SUBRAMANIAN; FERGUSON; TOKTAY, 2013).

Selection of the components for remanufacturing is largely affected by the disassembly process. Parameters which influence disassembly of the component are also useful criteria for the selection of the components for remanufacturing (HATCHER; IJOMAH; WINDMILL, 2011). 
DOI: 10.14807/ijmp.v11i1.942

In this paper, focus is on the selection and optimization of suitable components for remanufacturing. Optimization may be defined as the minimization of unnecessary traits and maximization of necessary ones, to find the most effective and highest attainable performance (SAHARE et al., 2018). In this study, different parameters were considered which affects the viability in remanufacturing as well as impacts the recovery of a product during remanufacturing.

Powerful and robust computational intelligence techniques like Fuzzy-TOPSIS and Taguchi were used in this research for selection of bearings for remanufacturing. FuzzyTOPSIS is a perfect blend of multi-criteria decision methods and fuzzy set theory which handles uncertain and incomplete information (MANICKAM, 2016).

Taguchi method is used to decrease the sensitivity of engineering designs towards ungovernable noise or factors (PANDEY; DUBEY, 2012). Taguchi method uses S/N ratio which shows experimental data quality characteristics for better optimization results.

\section{HYBRID FUZZY-TOPSIS \& TAGUCHI OPTIMIZATION}

Fuzzy refers to the situation whose set of activity boundaries are not well defined. TOPSIS is a widely adopted MCDM technique to solve multiple-criteria decision-making problems in various fields (HAMDAN; SARHAN; HAMDI, 2012). Fuzzy-TOPSIS is domain independent and thus may be applied virtually to any problem. Several research groups like Shiraz, Mirac, Sengul and coworkers (SENGUL et al., 2015; SHIRAZ et al., 2014; BAKIRCI et al. 2014; SENGUL et al., 2016; EREN, 2018; SHIVAKOTI et al., 2017; DIYALEY et al., 2017; DAS et al., 2017; RAGAVENDRAN et al., 2018; AIKHUELE et al., 2017; AIKHUELE et al., 2017; AZIZI et al., 2015) has regularly used Fuzzy-TOPSIS or its variants in a wide range of problems.

Taguchi Analysis is implemented in four steps which are - (i) Design of Experiments (DOE) (ii) selection of model (iii) analysis of responses (iv) desirability function analysis. The traditional experimental design results in a very large number of experiments. DOE endeavors to plan systematic conduction of experiments to acquire data in an intelligent and controlled manner with minimum efforts.

The process can be divided broadly into three parts as System; Input Factors and Responses. The system can be considered as the heart of the process (KIVAK; SAMTACS; CICEK, 2012). Input factors are variable signals which serve as starting mechanisms of the 


\section{INDEPENDENT JOURNAL OF MANAGEMENT \& PRODUCTION (IJM\&P)}

http://www.ijmp.jor.br

v. 11, n. 1, January-February 2020

ISSN: 2236-269X

DOI: 10.14807/ijmp.v11i1.942

process. With the help of Fuzzy-TOPSIS, input factors such as various diameters of outer race, inner race and roller diameter combinations were finalized and utilized in Taguchi analysis.

The response is nothing but the performance output of the system. In this case, responses were outer race surface roughness, inner race surface roughness, roller surface roughness, and outer race roundness, inner race roundness, roller roundness, outer race weight, inner race weight and roller weight.

Data obtained from DOE provides the information necessary to establish the relationship between the specified input factors and the responses of the given process. The possible values of input factors are termed as levels. The selection of the input factors, their levels and responses are the most important and critical stage in the analysis. In DOE when all possible combinations of given input factor levels are considered, it is termed as a full factorial design (FFD) (GUNAY; YUCEL, 2013).

However, in this study only existing product combinations of bearings were considered for analysis. An empirical model is selected to establish the relationship that exists between the design input factors and the response. A regression model is selected here and it also referred to as the main effect model. The main effect model needs a smaller number of experiments than its extension. Each experiment corresponds to a set of responses.

The response values acquired from comparatively few experiments enables response prediction for FFD. As this is a multi-response optimization problem, a popular simultaneous optimization approach is employed. The optimal solutions were arranged in the descending order of their combined desirability value. This feature of Taguchi analysis can be used to acquire multiple optimal solutions. In this paper Design-Expert version 11 software was used for implementation of Taguchi Analysis.

\section{ROLLER BEARINGS SELECTION}

The development of roller bearings and its components has been a research objective for more than five decades (WEINZAPFEL; SADEGHI, 2009). Roller bearings technically comprise of four components namely outer ring, inner ring, roller elements and cage (LU et al., 2013). We selected N308 bearing manufactured by Austin Engineering Company, Gujarat, India for our analysis. We collected two used bearings each from different cities having different climatic conditions namely Mumbai, Delhi, Guwahati, Jaipur and Shimla for understanding the behavior of bearings with climatic conditions. The specifications of N308 
ISSN: $2236-269 X$

DOI: 10.14807/ijmp.v11i1.942

bearings are bore diameter (d) $40 \mathrm{~mm}$, outer diameter (D) $90 \mathrm{~mm}$, width (B) $23 \mathrm{~mm}$ and weight (g) 662 grams. Fig. 1 shows the different parts of the N308 Bearings.

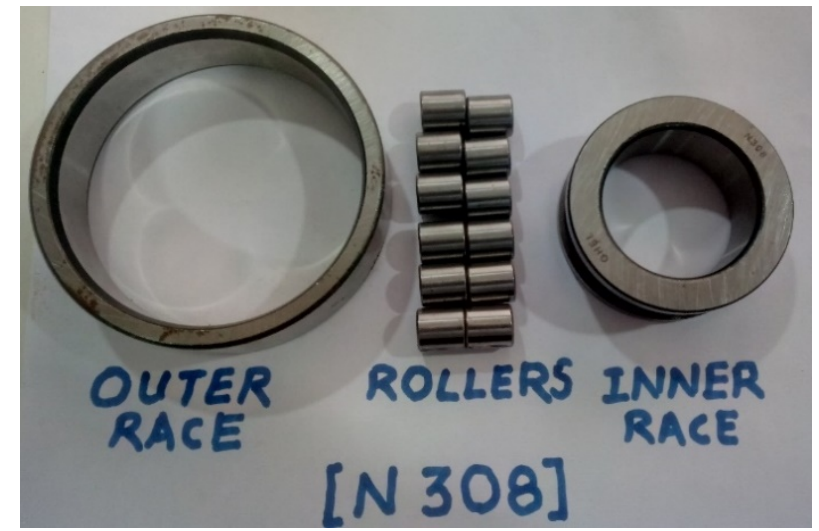

Figura 1: N308 Bearing Parts

Using Fuzzy-TOPSIS, we observed that the roundness, surface roughness and weight play a vital role for design for remanufacturing of roller bearings. Change in diameter, change in thickness and change in width were the least preference (SELVARAJ; MARAPPAN, 2011; SERVAIS; DUQUENNE; BOZET, 2013).

We carried out roundness test in Carl Zeiss Rondcom 41C. Surface roughness was checked in Carl Zeiss Surfcom S130. The weight was measured using mLabs_SF400C, ASIN: B07B1XKKGW capacity $600 \mathrm{~g} / 10 \mathrm{mg}$ readability $0.01 \mathrm{~g} / \mathrm{minimum}$ weight $0.05 \mathrm{~g}$, weight balance. We measured inside diameter of outer race and outside diameter of inner race and the roller diameter was taken as a mean of all the rollers diameters in the bearings. We used the three-point technique to measure the diameters with a coordinate measuring machine (GmbH Carl Zeiss Contour G2, Capacity: Size 700 X 700 X 600 mm).

\section{TESTING PARAMETERS SELECTION}

We used Fuzzy-TOPSIS analysis for testing parameter selection. Linguistic variables R1, R2, R3, R4, R5, R6 were assigned to various impacts of testing, like remanufacture ability, quality, level of integration, cost saving, End of life condition and durability. Similarly, P1, P2, P3, P4, P5, and P6 were assigned for the testing parameters. The linguistic variables and testing parameters are reported in Table 1.

Table 1: Linguistic variables and testing parameters

\begin{tabular}{|l|l|l|l|}
\hline Requirements & Description & Parameters & Description \\
\hline R1 & Remanufacture ability & P1 & Surface Roughness \\
\hline R2 & quality & P2 & change in Diameter \\
\hline R3 & Level of Integration & P3 & change in Thickness \\
\hline R4 & Cost saving & P4 & Change in Width \\
\hline R5 & EOL condition & P5 & Weight \\
\hline
\end{tabular}


INDEPENDENT JOURNAL OF MANAGEMENT \& PRODUCTION (IJM\&P)

http://www.ijmp.jor.br

v. 11, n. 1, January-February 2020

ISSN: 2236-269X

DOI: 10.14807/ijmp.v11i1.942

\begin{tabular}{|l|l|l|l}
\hline R6 & Durability & P6 & Roundness \\
\hline
\end{tabular}

Table 2: Fuzzy number allotment for Requirements and Testing's parameters

\begin{tabular}{|l|l|l|l|l|l|}
\hline \multicolumn{2}{|l|}{ Requirements for Design of Remanufacturing } & \multicolumn{2}{l|}{ Testing’s parameters } \\
\hline & Notation & Fuzzy No & & Notation & Fuzzy No \\
\hline Not important & A & $(0,0,0.1)$ & Very poor & P & $(0,0,0.1)$ \\
\hline Less important & B & $(0,0.1,0.3)$ & Medium poor & Q & $(0,0.1,0.3)$ \\
\hline Medium Less important & C & $(0.1,0.3,0.5)$ & Poor & R & $(0.1,0.3,0.5)$ \\
\hline Medium important & D & $(0.3,0.5,0.7)$ & Fair & S & $(0.3,0.5,0.7)$ \\
\hline Medium high important & E & $(0.5,0.7,0.9)$ & Good & T & $(0.5,0.7,0.9)$ \\
\hline High important & F & $(0.7,0.9,1)$ & Very Good & U & $(0.7,0.9,1)$ \\
\hline Very high important & G & $(0.9,1,1)$ & Excellent & V & $(0.9,1,1)$ \\
\hline
\end{tabular}

The results are classified as very poor, medium poor, poor, fair, good, very good and excellent (Table 2). The notation and the fuzzy number of each of the six grades for both requirements for the design of remanufacturing and testing's parameters were made with respect to triangular membership function.

Table 3 highlights the opinions given by three decision makers (DM1, DM2, DM3) on requirements for the design of remanufacturing. We took DM as design engineers from bearing manufacturing industries. The same decision maker's opinion regarding the requirements for the design of remanufacturing with respect to testing's parameters was taken in order to enhance the design for remanufacturing (Table 4). Based on the aggregate fuzzy numbers obtained, fuzzy numbers are assigned to the linguistic variables suggested by the decision maker. The values of normalized fuzzy decision matrix are weighted by multiplying them with the relevant aggregated fuzzy number (Table 5).

Table 3: Design makers opinion

\begin{tabular}{|l|l|l|l|l|}
\hline Requirements for design of remanufacturing & DM1 & DM2 & DM3 & Aggregate Fuzzy No. \\
\hline R1 & G & F & G & $(0.84,0.97,1)$ \\
\hline R2 & E & G & F & $(0.7,0.87,0.97)$ \\
\hline R3 & E & F & C & $(0.44,0.64,0.8)$ \\
\hline R4 & F & D & E & $(0.5,0.7,0.87)$ \\
\hline R5 & C & E & F & $(0.44,0.64,0.8)$ \\
\hline R6 & G & F & F & $(0.76,0.93,1)$ \\
\hline
\end{tabular}

Table 4: Decision maker's opinion about requirements for design of remanufacturing with respect to testing's parameters

\begin{tabular}{|l|l|l|l|l|l|l|}
\hline & R1 & R2 & R3 & R4 & R5 & R6 \\
\hline P1 & T & T & T & P & R & S \\
\hline P2 & V & S & U & R & U & S \\
\hline P3 & U & T & U & Q & S & S \\
\hline P4 & V & S & U & T & Q & R \\
\hline P5 & T & U & U & R & T & T \\
\hline P6 & V & V & V & V & U & U \\
\hline
\end{tabular}


DOI: $10.14807 /$ ijmp.v11i1.942

Table 5: Weighed normalized fuzzy decision matrix

\begin{tabular}{|l|l|l|l|l|l|l|}
\hline & R1 & R2 & R3 & R4 & R5 & R6 \\
\hline P1 & $(0.58,0.87,1)$ & $(0.35,0.60,0.60)$ & $(0.22,0.44,0.72)$ & $(0.45,0.7,0.87)$ & $(0.04,0.19,0.4)$ & $(0.22,0.46,0.7)$ \\
\hline P2 & $(0.75,0.97,1)$ & $(0.21,0.43,0.67)$ & $(0.30,0.57,0.8)$ & $(0.05,0.21,0.43)$ & $(0.30,0.57,0.8)$ & $(0.22,0.46,0.7)$ \\
\hline P3 & $(0.58,0.87,1)$ & $(0.35,0.60,0.60)$ & $(0.30,0.57,0.8)$ & $(0,0.07,0.26)$ & $(0.13,0.32,0.56)$ & $(0.22,0.46,0.7)$ \\
\hline P4 & $(0.75,0.97,1)$ & $(0.21,0.43,0.67)$ & $(0.30,0.57,0.8)$ & $(0.25,0.49,0.78)$ & $(0,0.06,0.24)$ & $(0.07,0.27,0.5)$ \\
\hline P5 & $(0.42,0.67,0.9)$ & $(0.49,0.78,0.97)$ & $(0.30,0.57,0.8)$ & $(0.05,0.21,0.43)$ & $(0.22,0.44,0.72)$ & $(0.38,0.65,0.9)$ \\
\hline P6 & $(0.75,0.87,1)$ & $(0.63,0.87,0.97)$ & $(0.39,0.64,0.8)$ & $(0.45,0.7,0.87)$ & $(0.30,0.57,0.8)$ & $(0.53,0.83,1)$ \\
\hline
\end{tabular}

Next, the ranking of the testing parameters was obtained using the relations below.

D* represents the Fuzzy Positive Ideal Solutions (FPIS D*).

$\mathrm{D}^{*}=\Sigma 1 / 2[\max (|1 \mathrm{st}-1| ;|3 r d-1|)+(2 \mathrm{nd}-1)]$

Here, the values $\mid 1$ st $-1 \mid$ and $|3 r d-1|$ from weighed normalized decision matrix are compared. The greater of the 2 values is added to (2nd -1 ).

D\# represents the Fuzzy Negative Ideal Solutions (FNIS D\#).

$\mathrm{D} \#=\Sigma 1 / 2[\max (|1 \mathrm{stb} b ;-0|,|3 r d-0|)+|2 \mathrm{nd}-0|]$

Here, the values $\mid 1$ st- $0 \mid$ and $|3 r d-0|$ from weighed normalized decision matrix are compared. The greater of the 2 values is added to (2nd-0).

Relative closeness coefficient of strategies $\left(C^{*}\right)=\mathrm{D \# /}\left(\mathrm{D}^{*+} \mathrm{D \#}\right)$

Table 6: Ranking of Testing's Parameters

\begin{tabular}{|l|l|l|l|l|}
\hline Piston & $\mathrm{D}^{*}$ & $\mathrm{D} \#$ & $\mathrm{C}^{*}=\mathrm{D}-/\left(\mathrm{D}^{*+D}\right.$ \#) & RANK \\
\hline P1 & 3.44 & 3.695 & 0.518 & 2 \\
\hline P2 & 3.48 & 3.805 & 0.522 & 4 \\
\hline P3 & 3.765 & 3.405 & 0.474 & 5 \\
\hline P4 & 3.815 & 3.39 & 0.470 & 6 \\
\hline P5 & 3.41 & 4.02 & 0.541 & 3 \\
\hline P6 & 2.235 & 4.76 & 0.680 & 1 \\
\hline
\end{tabular}

From the Fuzzy-TOPSIS analysis, we found that roundness ranks first followed by surface roughness, weight, change in diameter, change in thickness, and change in width. The rankings and relative closeness coefficient are reported in Table 6.

\section{TAGUCHI OPTIMIZATION ANALYSIS}

The surface roughness of outer race measured from inside face and inner race measured from outside face. Values obtained from the testing are reported in Table 7. For this experiment, we used the following notations - outer race diameter (F1); inner race diameter (F2); roller diameter (F3); outer race surface roughness (R1); inner race surface roughness (R2); roller surface roughness (R3); outer race roundness (R4); inner race roundness (R5); roller roundness 


\section{INDEPENDENT JOURNAL OF MANAGEMENT \& PRODUCTION (IJM\&P)}

http://www.ijmp.jor.br

v. 11, n. 1, January-February 2020

ISSN: 2236-269X

DOI: 10.14807/ijmp.v11i1.942

(R6); outer race weight (R7); inner race weight (R8) and roller weight (R9). The data of 11 bearings were considered for analyses. The signal to noise ratio is calculated using the difference between the minimum and maximum response value and the standard deviation. Signal-to-Noise ratio was set as per data in Table 8. An optimized design is made by determining the parameters and their values. The data was feed in the software where the parameters were specified with their respective values as shown in Table 9.

Table 7: Testing results for selected bearings

\begin{tabular}{|l|l|l|l|l|l|l|l|l|l|l|l|l|}
\hline Bearing no & F 1 & F 2 & F 3 & R 1 & R 2 & R3 & R4 & R5 & R 6 & R 7 & R 8 & R 9 \\
\hline 1 & 77.5247 & 53.5025 & 12.0071 & 0.131 & 0.079 & 0.106 & 3.5 & 6 & 0.001 & 283.203 & 207.141 & 11.2844 \\
\hline 2 & 77.5398 & 53.4566 & 12.0007 & 0.341 & 0.234 & 0.213 & 13 & 12.4 & 0.003 & 275.365 & 208.407 & 10.3439 \\
\hline 3 & 77.5083 & 53.5937 & 11.9957 & 0.267 & 0.658 & 1.156 & 4.7 & 9 & 0.0026 & 276.641 & 206.576 & 10.4011 \\
\hline 4 & 77.5183 & 53.4100 & 12.0134 & 0.293 & 0.155 & 0.332 & 8 & 251 & 0.0017 & 279.293 & 204.695 & 10.4361 \\
\hline 5 & 77.5458 & 53.4308 & 11.9583 & 1.381 & 0.675 & 1.45 & 120 & 30 & 0.0068 & 270.579 & 199.621 & 10.2388 \\
\hline 6 & 77.5039 & 53.5413 & 11.9655 & 0.837 & 0.814 & 1.422 & 13 & 63 & 0.0024 & 276.919 & 201.181 & 10.415 \\
\hline 7 & 77.5438 & 53.4570 & 11.8234 & 0.238 & 0.224 & 0.589 & 41 & 18 & 0.0068 & 282.843 & 199.934 & 9.8912 \\
\hline 8 & 77.5596 & 53.4617 & 12.0431 & 0.809 & 0.255 & 0.129 & 15 & 17 & 0.0021 & 276.158 & 207.732 & 10.4629 \\
\hline 9 & 77.5192 & 53.5189 & 12.0145 & 0.145 & 0.25 & 0.38 & 15.9 & 9 & 0.002 & 273.587 & 203.041 & 10.3922 \\
\hline 10 & 77.5086 & 53.3786 & 12.0041 & 0.554 & 0.307 & 0.711 & 17 & 18 & 0.0036 & 273.912 & 206.006 & 10.1073 \\
\hline 11 & 77.4961 & 53.4869 & 12.0081 & 1.409 & 0.509 & 0.347 & 68 & 9 & 0.0027 & 277.053 & 209.666 & 10.3417 \\
\hline
\end{tabular}

Table 8: S/N ratio for all responses

\begin{tabular}{|l|l|l|l|l|l|}
\hline Response & Minimum & Maximum & Mean & Std. Dev. & S/N Ratio \\
\hline R1 & 0.131 & 1.409 & 0.5823 & 0.4683 & 10.76 \\
\hline R2 & 0.079 & 0.814 & 0.3782 & 0.2437 & 10.30 \\
\hline R3 & 0.106 & 1.45 & 0.6214 & 0.5015 & 13.68 \\
\hline R4 & 3.5 & 120 & 29.01 & 35.57 & 34.29 \\
\hline R5 & 6 & 251 & 40.22 & 71.73 & 41.83 \\
\hline R6 & 0.001 & 0.0068 & 0.0032 & 0.0019 & 6.80 \\
\hline R7 & 270.579 & 283.203 & 276.87 & 3.79 & 1.05 \\
\hline R8 & 199.621 & 209.666 & 204.91 & 3.49 & 1.05 \\
\hline R9 & 9.8912 & 11.2844 & 10.39 & 0.3412 & 1.14 \\
\hline
\end{tabular}

Table 9: Constraints used for optimization analysis

\begin{tabular}{|l|l|l|l|}
\hline Name & Goal & Lower Limit & Upper Limit \\
\hline R1 & minimize & 0.361939 & 1.18701 \\
\hline R2 & minimize & 0.281069 & 0.902219 \\
\hline R3 & minimize & 0.325576 & 1.20416 \\
\hline R4 & minimize & 1.87083 & 10.9545 \\
\hline R5 & minimize & 2.44949 & 15.843 \\
\hline R6 & minimize & 0.001 & 0.0068 \\
\hline R7 & maximize & 270.579 & 283.203 \\
\hline R8 & maximize & 199.621 & 209.666 \\
\hline R9 & maximize & 9.8912 & 11.2844 \\
\hline
\end{tabular}

Table 10: Ranking of bearings

\begin{tabular}{|l|l|l|l|l|l|l|l|l|l|l|}
\hline Bearing No & R1 & R2 & R3 & R4 & R5 & R6 & R7 & R8 & R9 & Desirability \\
\hline 1 (new) & 0.131 & 0.079 & 0.106 & 3.500 & 6. & 0.001 & 283.203 & 207.141 & 11.284 & 0.968 \\
\hline 2 & 0.341 & 0.234 & 0.213 & 13.000 & 12.4 & 0.003 & 275.365 & 208.407 & 10.344 & 0.654 \\
\hline 8 & 0.809 & 0.255 & 0.129 & 15.000 & 17. & 0.002 & 276.158 & 207.732 & 10.463 & 0.637 \\
\hline 9 & 0.145 & 0.250 & 0.380 & 15.900 & 9. & 0.002 & 273.587 & 203.041 & 10.392 & 0.581 \\
\hline 3 & 0.267 & 0.658 & 1.156 & 4.700 & 9. & 0.003 & 276.641 & 206.576 & 10.401 & 0.483 \\
\hline 10 & 0.554 & 0.307 & 0.711 & 17.000 & 18. & 0.004 & 273.912 & 206.006 & 10.107 & 0.472 \\
\hline 6 & 0.837 & 0.814 & 1.422 & 13.000 & 63. & 0.002 & 276.919 & 201.181 & 10.415 & 0.006 \\
\hline
\end{tabular}


DOI: $10.14807 /$ ijmp.v11i1.942

Table 10 shows the best seven bearings which were selected for remanufacturing by Taguchi analysis having a positive desirability ratio ranging from 0.006 to 0.968 . Bearing no. 1 is a new bearing taken for reference purposes. This shows Taguchi analysis provided the significant results in the selection of bearings for remanufacturing and correspondingly all the bearing were graded as per the degradation of the bearing and four bearings we rejected due to excessive degradation over the lifetime. However, $60 \%$ of the old bearings were selected for remanufacturing by the analysis directly without doing any modification.

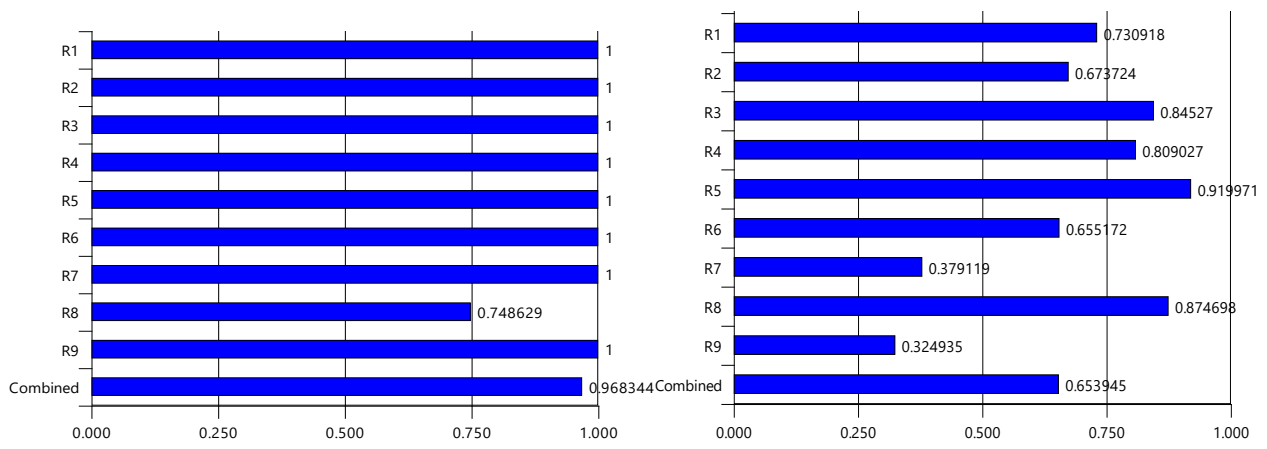

Figure 2: (a) Desirability curve for bearing no. 1(new) (b) Desirability curve for bearing no. 2

Figure 2(a) shows the new bearing desirability curve and for that, we achieved a combined desirability value of 0.968 . This shows even the new bearing having a slight variation from the optimized values. The desirability of all the testing parameters was achieved $100 \%$ except for the inner race weight which has a desirability of 0.74 . This decrease in desirability is due to the manufacturing tolerance range set by the original equipment manufacturer which is acceptable.

Figure 2(b) shows the desirability curve for old used bearing no. 2. A combined desirability value of 0.635 was obtained for this case. The highest desirability value was for the inner race roundness and the lowest was inner race weight. The result shows that the inner race parameters are having both the lowest and highest desirability value but both are in the acceptable range.
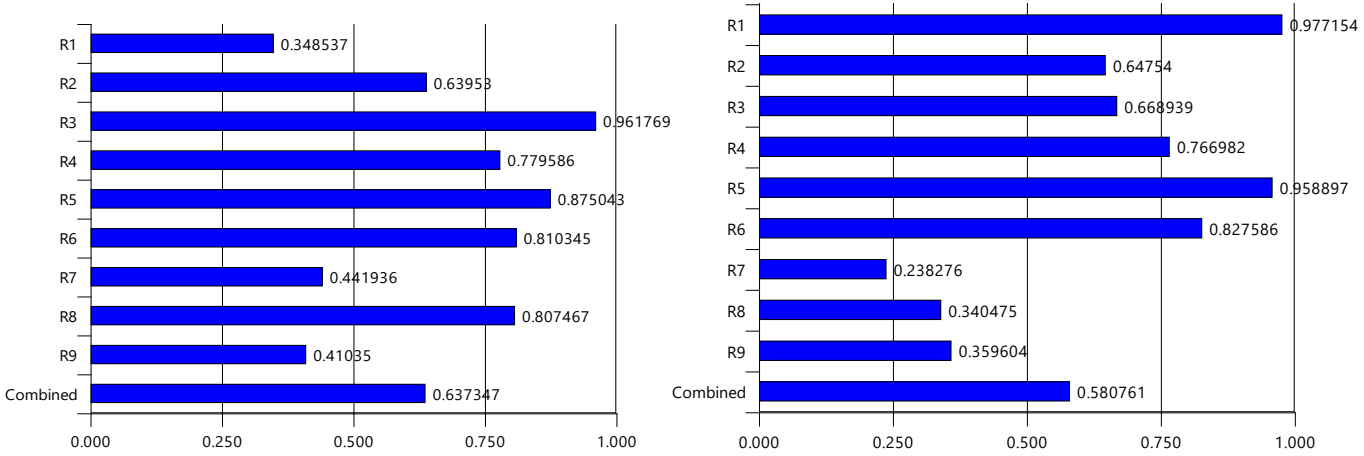

Figure 3: (a) Desirability curve for bearing no. 8, (b) Desirability curve for bearing no. 9 
DOI: $10.14807 /$ ijmp.v11i1.942

Figure 3(a) shows the desirability curve for old used bearing no. 8 and for that, a combined desirability value of 0.637 was achieved. The highest desirability value was for the roller surface roughness and the lowest was inner race weight. The result shows that the inner race parameters are having lowest desirability value and second highest desirability value but both are in the acceptable range.

Figure 3(b) shows the desirability curve for old used bearing no. 9 having a combined desirability value of 0.580 . The highest desirability value was for the outer race roundness and the lowest was outer race weight. The result shows that the outer race parameters are having both the lowest and highest desirability value but both are in the acceptable range.
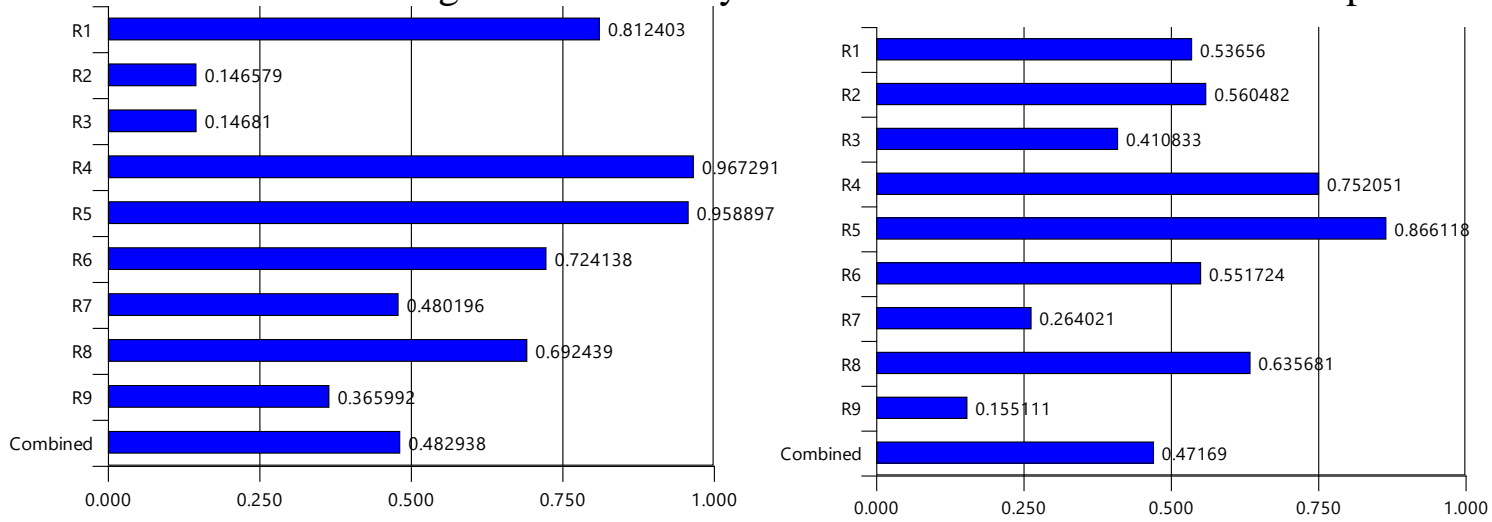

Figure 4: (a) Desirability curve for bearing no. 3 (b) Desirability curve for bearing no. 10

Figure 4(a) shows the desirability curve for old used bearing no. 3 with a combined desirability value of 0.483 . The highest desirability value was for the outer race roundness and the lowest was inner race surface roughness. The desirability curve for bearing no. 10 was reported in Figure $4(\mathrm{~b})$ and has a combined desirability value of 0.471 . The highest desirability value was for the inner race roundness and the lowest was roller weight.

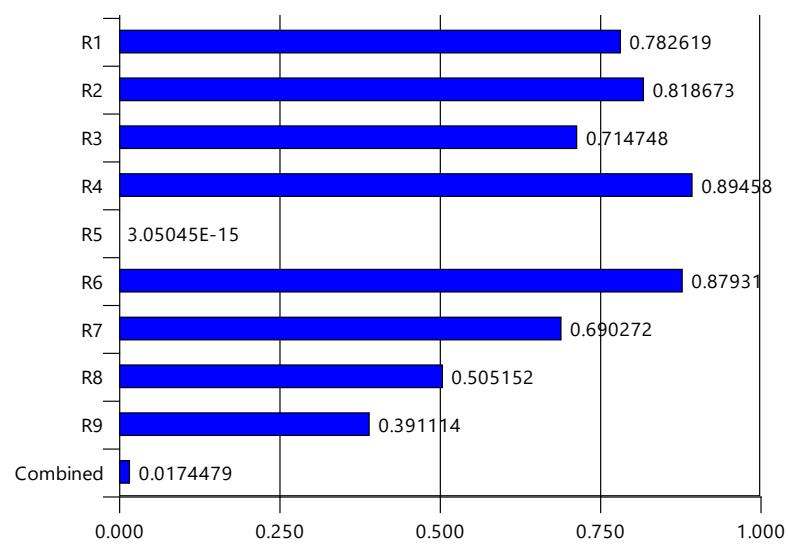

Figure 5: Desirability curve for bearing no. 6

Figure 5 shows the desirability curve for old used bearing no. 6 and for that, we achieved a combined desirability value of 0.0174 . The highest desirability value was for the outer race roundness and the lowest was inner race roundness. From the overall desirability values, it has 
DOI: 10.14807/ijmp.v11i1.942

been observed that both inner race and outer race roundness have not changed from the original dimensions. However the roller weight was getting reduced in most of the old bearings. This phenomenon is due to wear. This study reveals that the failure of the roller is usually because of the outer race roundness.

\section{CONCLUSION}

Using advanced computational intelligence techniques like Fuzzy-TOPSIS and Taguchi analysis, we tried to understand the feasibility of roller bearing for design for remanufacturing. In our study, we achieved a combined desirability of 0.968 giving maximum importance to all the testing parameters and compromising slightly in inner race weight with the individual desirability of 0.748 on a scale of 1 .

Overall in bearings which were selected by Taguchi analysis, the roundness of inner race and outer race were found to be the most influential parameters in deciding the selection of bearing for remanufacturing. The results suggest the bearing designers to design the bearing in such a way that the roundness of both races will be taken care off while manufacturing a bearing. The weight of the rollers was found to be the least influential parameter in deciding the selection of bearing for remanufacturing.

The result obtained from Taguchi analysis was seen to be similar to Fuzzy-TOPSIS analysis which infuses further confidence in the findings. As expected in the analysis, the bearing ranking one was the new one, this shows that roller bearing selection using Taguchi desirability analysis is a significant one. The study successfully highlighted the potential of remanufacturing of bearing strategy in Indian region since more than $50 \%$ of the bearings used in the analysis were selected for remanufacturing.

\section{REFERENCES}

AIKHUELE, D. O.; FAIZ, M. T.; ODOFIN, S. M.; ANSAH, R. H. (2017) Interval-Valued Intuitionistic Fuzzy Topsis-Based Model For Troubleshooting Marine Diesel Engine Auxiliary System. International Journal Maritime Engineering, v. 159, p. 107-114. DOI: http://umpir.ump.edu.my/id/eprint/16772

AIKHUELE, D. O.; SOROOSHIAN, S.; ANSAH, R. H.; TURAN, F. M. (2017) Application of Intuitionistic Fuzzy Topsis Model for Troubleshooting an Offshore Patrol Boat Engine.

Polish Maritime Research, n. 24, p. 68-76. DOI: https://doi.org/10.1515/pomr-2017-0051

AYDIN, R.; KWONG, C. K.; JI, P. (2015) A novel methodology for simultaneous consideration of remanufactured and new products in product line design. International journal of production economics, n. 169, p. 127-140. DOI: https://doi.org/10.1016/j.ijpe.2015.07.022

AZIZI, A.; AIKHUELE, D. O.; SOULEMAN, F. S. (2015) A Fuzzy TOPSIS Model to Rank 
ISSN: $2236-269 X$

DOI: 10.14807/ijmp.v11i1.942

Automotive Suppliers. Procedia Manufacturing, n. 2, p. 159-164. DOI: https://doi.org/10.1016/j.promfg.2015.07.028

BAKIRCI, F.; SHIRAZ, S. E.; SATTARY, A. (2014) BIST'da Demir, Celik Metal Ana Sanayii Sektorunde Faaliyet Gosteren Isletmelerin Finansal Performans Analizi: VZA Super Etkinlik ve TOPSIS Uygulamasi/Financial Performance Analysis of Iron, Steel Metal Industry Sector Companies in The Borsa Istanbul: DEA Super Efficiency and TOPSIS Methods. Ege Akademik Bakis, 14, 9.

BENKHEROUF, L.; SKOURI, K.; KONSTANTARAS, I. (2016) Optimal control of production, remanufacturing and refurbishing activities in a finite planning horizon inventory system. Journal of Optimization Theory and Applications, n. 168, p. 677-698. DOI: https://doi.org/10.1007/s10957-015-0741-9

DAS, P. P.; GUPTA, P.; GHADAI, R. K.; RAMACHANDRAN, M.; KALITA, K. (2017) Optimization of turning process parameters by Taguchi-based Six Sigma. Mechanics and Mechanical Engineering, n. 21, p. 649-656.

DINDARIAN, A.; GIBSON, A. A.; QUARIGUASI-FROTA-NETO, J. (2012) Electronic product returns and potential reuse opportunities: a microwave case study in the United Kingdom. Journal of Cleaner Production, n. 32, p. 22-31. DOI:

https://doi.org/10.1016/j.jclepro.2012.03.015

DIYALEY, S.; SHILAL, P.; SHIVAKOTI, I.; GHADAI, R. K.; KALITA, K. (2017) PSI and TOPSIS Based Selection of Process Parameters in WEDM. Periodica Polytechnica Mechanical Engineering, n. 61, p. 255-260. DOI: https://doi.org/10.3311/PPme.10431

EREN, M. (2018) forecasting of the fuzzy univariate time series by the optimal lagged regression structure determined based on the genetic algorithm. Economic Computation \& Economic Cybernetics Studies \& Research, v. 52, n. 2

FEGADE, V.; SHRIVATSAVA, R. L.; KALE, A. V. (2015) Design for Remanufacturing: Methods and their Approaches. Materials Today: Proceedings, n. 2, p. 1849-1858. DOI: https://doi.org/10.1016/j.matpr.2015.07.130

FORD, S.; DESPEISSE, M. (2016) Additive manufacturing and sustainability: an exploratory study of the advantages and challenges. Journal of Cleaner Production, n. 137, p. 1573-1587. DOI: https://doi.org/10.1016/j.jclepro.2016.04.150

GUNAY, M.; YUCEL, E. (2013) Application of Taguchi method for determining optimum surface roughness in turning of high-alloy white cast iron. Measurement, n. 46, p. 913-919. DOI: https://doi.org/10.1016/j.measurement.2012.10.013

HAMDAN, A.; SARHAN, A. A.; HAMDI, M. (2012) An optimization method of the machining parameters in high-speed machining of stainless steel using coated carbide tool for best surface finish. The International Journal of Advanced Manufacturing Technology, n. 58, p. 81-91. DOI: https://doi.org/10.1007/s00170-011-3392-5

HATCHER, G. D.; IJOMAH, W. L.; WINDMILL, J. F. (2011) Design for remanufacture: a literature review and future research needs. Journal of Cleaner Production, n. 19, p. 20042014. DOI: https://doi.org/10.1016/j.jclepro.2011.06.019

HILGER, T.; SAHLING, F.; TEMPELMEIER, H. (2016) Capacitated dynamic production and remanufacturing planning under demand and return uncertainty. OR spectrum, n. 38, p. 849-876. DOI: https://doi.org/10.1007/s00291-016-0441-3

KENNE, J.-P.; DEJAX, P.; GHARBI, A. (2012) Production planning of a hybrid 
manufacturing--remanufacturing system under uncertainty within a closed-loop supply chain. International Journal of Production Economics, n. 135, p. 81-93. DOI: https://doi.org/10.1016/j.ijpe.2010.10.026

KIVAK, T.; SAMTACS, G.; CICEK, A. (2012) Taguchi method based optimisation of drilling parameters in drilling of AISI 316 steel with PVD monolayer and multilayer coated HSS drills. Measurement, n. 45, p. 1547-1557. DOI:

https://doi.org/10.1016/j.measurement.2012.02.022

KWAK, M.; KIM, H. (2015) Design for life-cycle profit with simultaneous consideration of initial manufacturing and end-of-life remanufacturing. Engineering Optimization, n. 47, p. 18-35. DOI: https://doi.org/10.1080/0305215X.2013.868450

LIU, M.; LIU, C.; XING, L.; LIU, Z.; LI, X.; LIN, L. (2016) Assembly process control method for remanufactured parts with variable quality grades. The International Journal of Advanced Manufacturing Technology, n. 85, p. 1471-1481. DOI: https://doi.org/10.1007/s00170-015-8026-X

LU, D.; ZHAO, W.; LU, B.; ZHANG, J. (2013) Cage speed of hydrodynamic rolling hybrid bearings. Tribology Letters, n. 51, p. 303-309. DOI: https://doi.org/10.1007/s11249013-0154-6

MANICKAM, R. (2016) Back propagation neural network for prediction of some shell moulding parameters. Periodica Polytechnica Mechanical Engineering, n. 60, p. 203-208. DOI: https://doi.org/10.3311/PPme.8684

PANDEY, A. K.; DUBEY, A. K. (2012) Taguchi based fuzzy logic optimization of multiple quality characteristics in laser cutting of Duralumin sheet. Optics and Lasers in Engineering, n. 50, p. 328-335. DOI: https://doi.org/10.1016/j.optlaseng.2011.11.005

PUROHIT, P.; RAMACHANDRAN, M. (2015) Selection of Flywheel Material using Multicriteria Decision Making Fuzzy Topsis. Indian Journal of Science and Technology, 8.33. DOI: https://doi.org/10.17485/ijst/2015/v8i33/80028

RAGAVENDRAN, U.; GHADAI, R. K.; BHOI, A.; RAMACHANDRAN, M.; KALITA, K. A. (2018) Sensitivity Analysis and Optimization of EDM Process Parameters.

Transactions of the Canadian Society for Mechanical Engineering.

DOI: https://doi.org/10.1139/tcsme-2018-0021

RAMACHANDRAN, M.; AGARWAL, N. (2017) Identification of Most Affected Parameter for Design for Remanufacturing of Scrap Piston by Taguchi Desirability Function Analysis. International Conference on Man--Machine Interactions, p. 320-329. DOI: https://doi.org/10.1007/978-3-319-67792-7_32

SAHARE, S. B.; UNTAWALE, S. P.; CHAUDHARI, S. S.; SHRIVASTAVA, R. L.; KAMBLE, P. D. (2018) Optimization of End Milling Process for Al2024-T4 Aluminum by Combined Taguchi and Artificial Neural Network Process. In Soft Computing: Theories and Applications, p. 525-535. Springer. DOI: https://doi.org/10.1007/978-981-10-56994_49

SELVARAJ, A.; MARAPPAN, R. (2011) Experimental analysis of factors influencing the cage slip in cylindrical roller bearing. The International Journal of Advanced

Manufacturing Technology, n. 53, p. 635-644. DOI: https://doi.org/10.1007/s00170-0102854-5

SENGUL, U.; EREN, M. (2016) Selection of digital marketing tools using fuzzy AHP-fuzzy TOPSIS. In Fuzzy Optimization and Multi-Criteria Decision Making in Digital 
DOI: 10.14807/ijmp.v11i1.942

Marketing, p. 97-126. DOI: https://doi.org/10.4018/978-1-4666-8808-7.ch005

SENGUL, U.; EREN, M.; SHIRAZ, S. E.; GEZDER, V.; SENGUL, A. B. (2015) Fuzzy TOPSIS method for ranking renewable energy supply systems in Turkey. Renewable Energy, n. 75, p. 617-625. DOI: https://doi.org/10.1016/j.renene.2014.10.045

SERVAIS, C.; DUQUENNE, M.; BOZET, J.-L. (2013) Influence of tribology of cage material on ball bearing cage instability. 15th European Space Mechanism and Tribology Symposium (ESMATS), p. 71-78.

SHIRAZ, S. E.; SENGUL, U.; EREN, M. (2014) Determination of extended fuzzy TOPSIS method of criteria leading to supplier selection for industries. Asian Social Science, n. 10, p. 183. DOI: https://doi.org/10.1007/s13369-017-2673-1

SHIVAKOTI, I.; PRADHAN, B. B.; DIYALEY, S.; GHADAI, R. K.; KALITA, K. (2017) Fuzzy TOPSIS-Based Selection of Laser Beam Micro-marking Process Parameters. Arabian Journal for Science and Engineering, n. 42, p. 4825-4831. DOI:

https://doi.org/10.1007/s13369-017-2673-1

SUBRAMANIAN, R.; FERGUSON, M. E.; BERIL TOKTAY, L. (2013) Remanufacturing and the component commonality decision. Production and Operations Management, n. 22, p. 36-53. DOI: https://doi.org/10.1111/j.1937-5956.2012.01350.x

SUGUMARAN, V.; RAMACHANDRAN, K. I. (2007) Automatic rule learning using decision tree for fuzzy classifier in fault diagnosis of roller bearing. Mechanical Systems and Signal Processing, n. 21, p. 2237-2247. DOI:

https://doi.org/10.1016/j.ymssp.2006.09.007

WEINZAPFEL, N.; SADEGHI, F. (2009) A discrete element approach for modeling cage flexibility in ball bearing dynamics simulations. Journal of Tribology, n. 131, p. 021-102. DOI: https://doi.org/10.1115/1.3063817

ZHANG, T.; CHU, J.; WANG, X.; LIU, X.; CUI, P. (2011) Development pattern and enhancing system of automotive components remanufacturing industry in China. Resources, Conservation and Recycling, n. 55, p. 613-622. DOI:

https://doi.org/10.1016/j.resconrec.2010.09.015 